Cornelia Brink

Ikonen der Vernichtung 

Cornelia Brink

\section{Ikonen der Vernichtung}

Öffentlicher Gebrauch von Fotografien aus nationalsozialistischen

Konzentrationslagern nach 1945

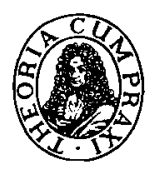

Akademie Verlag 
Gedruckt mit Unterstuitzung der Deutschen Forschungsgemeinschaft D 25

Die Deutsche Bibliothek - CIP-Einheitsaufnahme

\section{Brink, Cornelia:}

Ikonen der Vernichtung : öffentlicher Gebrauch von Fotografien aus nationalsozialistischen Konzentrationslagern nach 1945 / Cornelia Brink. - Berlin : Akad. Verl., 1998

(Schriftenreihe des Fritz-Bauer-Instituts ; Bd. 14)

ISBN 3-05-003211-1

(C) Akademie Verlag GmbH, Berlin 1998

Der Akademie Verlag ist ein Unternehmen der R. Oldenbourg-Gruppe.

Das eingesetzte Papier ist alterungsbeständig nach DIN/ISO 9706.

Alle Rechte, insbesondere die der Übersetzung in andere Sprachen, vorbehalten. Kein Teil dieses Buches darf ohne schriftliche Genehmigung des Verlages in irgendeiner Form - durch Photokopie, Mikroverfilmung oder irgendein anderes Verfahren - reproduziert oder in eine von Maschinen, insbesondere von Datenverarbeitungsmaschinen, verwendbare Sprache übertragen oder übersetzt werden.

Einbandgestaltung und Satz: Hans Herschelmann, Berlin

Druck: GAM Media, Berlin

Bindung: Druckhaus „Thomas Müntzer“, Bad Langensalza

Printed in the Federal Republic of Germany 